\title{
Spatial variability in tropospheric peroxyacetyl nitrate in the tropics from infrared satellite observations in 2005 and 2006
}

\author{
Vivienne H. Payne ${ }^{1}$, Emily V. Fischer ${ }^{2}$, John R. Worden ${ }^{1}$, Zhe Jiang ${ }^{3}$, Liye Zhu ${ }^{2}$, Thomas P. Kurosu ${ }^{1}$, and \\ Susan S. Kulawik ${ }^{4}$ \\ ${ }^{1}$ Jet Propulsion Laboratory, California Institute of Technology, Pasadena, California, USA \\ ${ }^{2}$ Department of Atmospheric Science, Colorado State University, Fort Collins, Colorado, USA \\ ${ }^{3}$ National Center for Atmospheric Research, Boulder, Colorado, USA \\ ${ }^{4}$ Bay Area Environmental Research Institute, Mountain View, California, USA
}

Correspondence to: Vivienne H. Payne (vivienne.h.payne@jpl.nasa.gov)

Received: 23 November 2016 - Discussion started: 22 December 2016

Revised: 31 March 2017 - Accepted: 12 April 2017 - Published: 24 May 2017

\begin{abstract}
Peroxyacetyl nitrate (PAN) plays a fundamental role in the global ozone budget and is the primary reservoir of tropospheric reactive nitrogen over much of the globe. However, large uncertainties exist in how surface emissions, transport and lightning affect the global distribution, particularly in the tropics. We present new satellite observations of free-tropospheric PAN in the tropics from the Aura Tropospheric Emission Spectrometer. This dataset allows us to test expected spatiotemporal distributions that have been predicted by models but previously not well observed. We compare here with the GEOS-Chem model with updates specifically for PAN. We observe an austral springtime maximum over the tropical Atlantic, a feature that model predictions attribute primarily to lightning. Over northern central Africa in December, observations show strong interannual variability, despite low variation in fire emissions, that we attribute to the combined effects of changes in biogenic emissions and lightning. We observe small enhancements in free-tropospheric PAN corresponding to the extreme burning event over Indonesia associated with the 2006 El Niño.
\end{abstract}

\section{Introduction}

Peroxyacetyl nitrate (PAN) provides a thermally unstable reservoir for nitrogen oxide radicals $\left(\mathrm{NO}_{x}\right)$, facilitating their long-range transport at low temperatures and eventual release in warmer regions of the remote troposphere where they most efficiently contribute to ozone $\left(\mathrm{O}_{3}\right)$ production (Singh and
Hanst, 1981). PAN chemistry effectively reduces $\mathrm{O}_{3}$ production in $\mathrm{NO}_{x}$ source regions and increases it in remote regions of the troposphere (Wang et al., 1998; Fischer et al., 2013). PAN is thought to be the dominant species in the reactive nitrogen budget over much of the globe (Roberts et al., 2007), but it is a particularly difficult compound to simulate in models due to the complexity of PAN chemistry and uncertainties in precursor emissions. Comprehensive in situ measurements of PAN are limited for the troposphere, particularly in the tropics (Maloney et al., 2001; Singh et al., 1996).

Since PAN abundance can be highly variable in space and time, it is difficult to know whether presently available but limited in situ measurements are broadly representative. Satellite measurements offer a new opportunity to place constraints on our understanding, providing global coverage over multiple years. Global measurements of PAN have previously been obtained via thermal-infrared measurements from the limb-viewing Atmospheric Chemistry Experiment Fourier Transform Spectrometer (ACE-FTS) and Michelson Interferometer for Passive Atmospheric Sounding (MIPAS) satellite sensors (Tereszchuk et al., 2013; Moore and Remedios, 2010; Wiegele et al., 2012; Pope et al., 2016). Limb sounding measurements of PAN for limited time periods, but at relatively high spatial density, have also been made from the Cryogenic Infrared Spectrometers and Telescopes for the Atmosphere (CRISTA), flown on the Space Shuttle for two separate missions in 1994 and 1997 (Ungermann et al., 2016) These observations provide information in the uppermost troposphere and lower stratosphere. Observations in the nadir- 
viewing geometry can provide sensitivity to PAN lower in the troposphere, where its variable stability makes its role in $\mathrm{O}_{3}$ production more important to understand. $\mathrm{PAN}$ is formed rapidly in biomass burning plumes, and isolated cases of elevated PAN in biomass burning plumes in the troposphere have been observed from the MetOp Infrared Atmospheric Sounding Instruments (IASI) and Aura Tropospheric Emission Spectrometer (TES) sensors (Clarisse et al., 2011; Alvarado et al., 2011). More recently, global measurements of tropospheric PAN from Aura-TES have been obtained and are described in Payne et al. (2014). These TES PAN retrievals have so far been utilized in studies of the influence of fires in atmospheric composition in boreal spring (Zhu et al., 2015), the role of PAN in seasonal transport of East Asian pollution (Jiang et al., 2016) and the seasonality and interannual variability of PAN in the eastern Pacific (Zhu et al., 2017). Here we present new observations of TES PAN in the tropics. We focus on 2005 and 2006 in austral spring (the season of peak biomass burning) and compare these observations with simulations from the GEOS-Chem global chemical transport model.

The tropical troposphere plays an important role in global oxidation capacity, and understanding the role of PAN chemistry is necessary to understand the different contributions to the $\mathrm{NO}_{x}$ reservoir and the $\mathrm{O}_{3}$ enhancement in the tropical south Atlantic. PAN can be formed within fire plumes because $\mathrm{NO}_{x}$ is co-emitted with large quantities of shortlived non-methane volatile organic compounds (NMVOCs), and it can form when biogenic NMVOCs react with $\mathrm{NO}_{x}$ produced by lightning. Formation of PAN in the cold upper troposphere over this region acts to sequester $\mathrm{NO}_{x}$ and decrease $\mathrm{O}_{3}$ formation. The contribution of biomass burning to the $\mathrm{NO}_{x}$ reservoir and the $\mathrm{O}_{3}$ enhancement in the tropical south Atlantic remains a long-standing issue (Anderson et al., 1993; Gregory et al., 1996; Jacob et al., 1996; Edwards et al., 2003; Ziemke et al., 2009). Models predict that lightning is the most important source of PAN in the atmosphere of the tropical south Atlantic (Fischer et al., 2014, and references therein). However, this finding is particularly sensitive to the description of boundary layer chemistry, which remains very uncertain (Hewitt et al., 2010). Implementation of a state-of-the-science isoprene scheme (Paulot et al., 2009a, b) reduces the model sensitivity of upper-tropospheric PAN over the tropical Atlantic to lightning by changing the fraction of isoprene oxidized outside the boundary layer (Fischer et al., 2014). Elevated PAN mixing ratios ( 500 pptv) were observed in the middle to upper troposphere over the tropical south Atlantic during the October 1992 TRACE-A aircraft campaign, and an austral spring maximum in this region is predicted by state-of-the-science global chemical transport models (Fischer et al., 2014; Fadnavis et al., 2014). Limb-viewing satellite observations have shown PAN mixing ratios of $\sim 350 \mathrm{pptv}$ at $260 \mathrm{hPa}$ in this region in austral spring (Moore and Remedios, 2010; Glatthor et al., 2007). PAN observations over multiple years, in conjunction with global chemical models, offer the potential to shed light on the influence of fire emissions on the interannual variability of the tropical south Atlantic $\mathrm{O}_{3}$ maximum.

Section 2 describes the characteristics of the TES PAN retrievals, while Sect. 3 provides background on the GEOSChem model simulations used in this work. Section 4 describes the features observed by TES in the tropics in austral spring of 2005 and 2006. Section 5 presents the relationships between PAN and carbon monoxide (CO) in different regions and discusses model-measurement comparisons. Conclusions are presented in Sect. 6.

\section{TES PAN retrievals}

The TES has been flying on the Aura satellite since 2004 . TES measures nadir-viewing spectrally resolved thermalinfrared radiances, providing information on numerous trace gases in the troposphere, including PAN. The TES PAN retrievals use an optimal estimation approach. An algorithm description is provided in Payne et al. (2014). TES has been shown to be capable of observing PAN with sensitivity to elevated concentrations (greater than $\sim 0.2-0.3 \mathrm{ppbv}$ ) in the free troposphere (between $\sim 800 \mathrm{mbar}$ and the tropopause). Estimated single-observation errors are $30-50 \%$. The number of degrees of freedom for signal (DOFS), or independent pieces of information, in the TES PAN retrievals is less than 1.0, meaning that the retrievals are not sensitive to the vertical distribution of PAN in the atmosphere. As discussed in Payne et al. (2014), TES PAN retrievals are generally insensitive to near-surface variations of PAN and are sensitive primarily to variations in the free troposphere. TES PAN retrievals are being processed routinely for the whole TES dataset and are publicly available in the TES v7 Level 2 product. However, at the time of this work, the $\mathrm{v} 7$ product was not yet available. The TES PAN retrievals shown here were processed using a prototype algorithm for the areas and time periods of interest.

PAN retrievals are not attempted for all TES targets. As discussed in Payne et al. (2014), PAN retrievals are not attempted for cases where the water vapor or $\mathrm{O}_{3}$ from previous retrieval steps did not pass the master quality flags. PAN retrievals are also generally not attempted over sandy or rocky surfaces, such as desert or mountainous regions. The reason for this is the presence of a silicate feature in the surface emissivity spectra of those surfaces that coincides with the spectral position of the PAN absorption feature. While this is not an issue for the tropical data, we note that PAN retrievals over icy or snowy surfaces are subject to a high bias. Again, this is due to spectral features in the emissivity for these surfaces. Therefore, we recommend screening out data with surface temperature less than $270 \mathrm{~K}$. Jiang et al. (2016) performed indirect comparisons of TES PAN with aircraft measurements from the Arctic Research of the Composition of the Troposphere from Aircraft and Satellites (ARCTAS) campaign, using the GEOS-Chem model as a transfer 
standard. Results of that study suggest a high bias in TES cases with surface temperatures below $\sim 280 \mathrm{~K}$, where surfaces are not ice or snow covered. One possible explanation is that surface temperature is a proxy for the representative temperature of the column and that the low bias stems from a lack of information on temperature dependence in the HITRAN 2008 spectroscopic cross sections used in the TES retrievals. The HITRAN 2012 database includes lowtemperature cross-section information for PAN. This will be considered for future versions of the TES algorithm. Based on the Jiang et al. (2016) comparisons for cases with warmer surfaces/atmospheres, we do not expect strong biases for the tropical data shown here.

We define cases for which elevated PAN is detected with confidence as those that pass basic quality checks and where the DOFS of the retrieval is greater than 0.6. Note that the use of DOFS is not, in itself, a quality flag. Retrievals with DOFS $<0.6$ may converge with a good quality of fit. However, in those cases the retrieved PAN would be strongly affected by the prior constraint chosen for the retrieval. Further justification of the choice of DOFS $=0.6$ as a threshold can be found in Payne et al. (2014).

\section{GEOS-Chem global chemical transport model}

GEOS-Chem (http://www.geos-chem.org) is a global chemical transport model driven by GEOS assimilated meteorological data from the NASA Global Modeling and Assimilation Office (GMAO). GEOS-Chem includes a state-of-thescience description of tropospheric oxidant chemistry. We used v9.01.01 with updates specifically for PAN as described in Fischer et al. (2014) (and references therein) to explore, analyze and explain the global TES PAN data. GEOS-Chem was driven by NASA GEOS-5 assimilated meteorological data with $0.5^{\circ} \times 0.67^{\circ}$ horizontal resolution, 47 vertical levels and 3-6h temporal resolution. We degraded the horizontal resolution to $2^{\circ} \times 2.5^{\circ}$. The simulations for 2005 and 2006 were preceded by a 1 -year spinup.

Briefly, the version described in Fischer et al. (2014) includes updated budgets of many NMVOC PAN precursors including acetone, ethane and propane, acetaldehyde and methylglyoxal. Terrestrial biogenic emissions of NMVOCs are calculated using the Model of Emissions of Gases and Aerosols from Nature (MEGAN v2.0) (Guenther et al., 2006). The model incorporates a new oxidation schemes for isoprene and several additional NMVOC tracers (monoterpenes, ethanol, aromatics) that also serve as PAN precursors. Other relevant updates include the treatment of emissions from fires. In particular, the model includes biomass burning emissions of shorter-lived NMVOCs (monoterpenes, aromatics); $40 \%$ of the biomass burning $\mathrm{NO}_{x}$ is directly emitted as PAN (Alvarado et al., 2010), and $35 \%$ of fire emissions are injected into the 10 model layers above the boundary layer (Val Martin et al., 2010).

\section{Observations of PAN in the tropics}

Figure 1 shows Aura-TES PAN in the tropics for October 2006. Figure 1a shows individual observations. Volume mixing ratios (VMRs) in Fig. 1a represent an average between $800 \mathrm{hPa}$ and the tropopause. Figure $1 \mathrm{~b}$ shows the fraction of observations with elevated PAN. This fraction is the ratio of the number of TES targets for which elevated PAN is detected with confidence to the number of targets for which the PAN retrieval was attempted. Figure $1 \mathrm{~b}$ was created by calculating the fraction of observations with elevated PAN in $4^{\circ} \times 5^{\circ}$ boxes, then smoothing this field with a twodimensional boxcar average with a width of two boxes. For October 2006, we see a high density of elevated PAN detections over the tropical south Atlantic and the surrounding landmasses and a high fraction of TES observations with elevated PAN over the tropical south Atlantic. High PAN over the tropical south Atlantic in austral spring is one of the major features in the global PAN distribution predicted by the GEOS-Chem (Fischer et al., 2014). High PAN values over the tropical south Atlantic in the uppermost troposphere $(\sim 8-16 \mathrm{~km})$ have previously been observed from MIPAS (Moore and Remedios, 2010; Glatthor et al., 2007; Pope et al., 2016). The TES observations presented here provide information on the temporal evolution in austral spring 2005 and 2006. We express the gridded results in "fraction of observations with elevated PAN", rather than averaged PAN retrieval values, because the Aura-TES PAN retrievals are only possible for elevated PAN values. The precise details of the detection threshold depend on a number of factors, including cloud optical depth, the vertical distribution of PAN in the atmosphere and the details of the surface and atmospheric temperatures. Since water is a significant interferent in the spectral region used for the PAN retrieval, there is also some dependence of the detection threshold on the details of the water vapor profile. The vertical sensitivity of the TES PAN retrievals also varies with these factors, although in general the retrievals have highest sensitivity to variations in PAN in the free troposphere. Based on simulations over a range of conditions, Payne et al. (2014) specify an approximate detection threshold of $0.2 \mathrm{ppbv}$. Therefore, the interpretation of any averaged values would be complicated by the fact that we do not have information on the values at the low end of the true distribution.

Figure 2 shows histograms of free-tropospheric average PAN values in different regions of the tropics for September through December 2005 and 2006. Boxes showing the geographical extent of each of these regions are shown in Fig. 1a. Histograms are calculated on a logarithmic scale in order to better allow examination of differences in the 0.1 to $0.3 \mathrm{ppbv}$ range. Histograms are normalized by the total number of TES observations in each region. Also shown for each region is the total of the histogram for each month and region. This total equates to the fraction of TES observations where elevated PAN was observed. It is clear from Fig. 2 that there is con- 


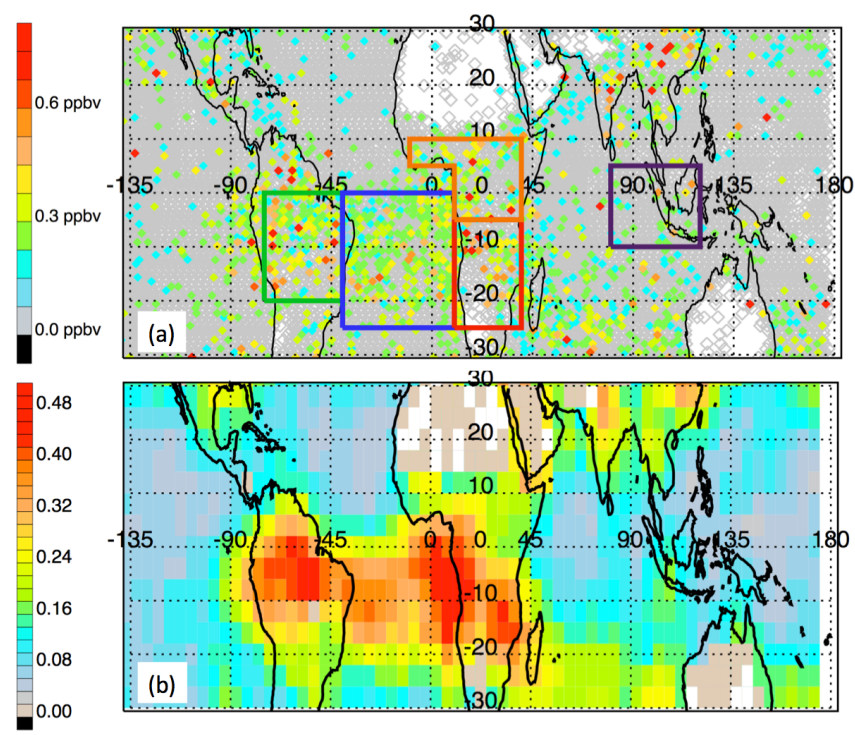

Figure 1. (a) Gray points show locations of TES measurements during October 2006 where PAN retrievals were attempted. Colored points show cases where elevated PAN was measured in the TES spectra, colored according to the average VMR between $800 \mathrm{hPa}$ and the tropopause. Values over $0.8 \mathrm{ppbv}$ are colored red. Boxes show regions highlighted in Figs. 2 and 5. (b) Fraction of TES measurements where elevated PAN was detected in TES spectra, showing a maximum in the tropical south Atlantic.

siderable variation in free-tropospheric PAN between regions and from one month to the next. In general, higher PAN values and higher fractions are observed for the months where peak biomass burning occurs in those regions. For the Amazon and southern Africa, peak burning occurs in September and October. For northern Africa, peak burning occurs in December. For Indonesia, peak burning usually occurs between September and November. For 2006, the Indonesian fires began in October and persisted through November (Logan et al., 2008).

In all TES retrievals, an effective cloud optical depth is retrieved in order to mitigate the impact of clouds (Kulawik et al., 2006). The impact of clouds is to reduce the sensitivity of the measured radiance to the target trace gas concentrations. This is accounted for in the averaging kernels and therefore is reflected in the DOFS for the retrieval. As discussed in Payne et al. (2014), clouds with optical depth greater than $\sim 0.5$ have the potential to obscure PAN signals that are comparable in magnitude to the instrument noise. We would therefore expect that the fractions shown in Figs. $1 \mathrm{~b}$ and 2 would be, if anything, an underestimate of the true incidence of elevated PAN in the atmosphere.
For all the months shown here, TES made global survey measurements throughout the tropics, and the sampling is vastly more spatially uniform than could be obtained by any kind of in situ sampling strategy. However, the number of TES measurements in the tropics does vary somewhat between the two years shown here, with a greater number of measurements taken in 2006 than 2005. The number of measurements in any given region does also vary from one month to the next, depending on the details of instrument operation. In both 2005 and 2006 there were significantly fewer global survey measurements taken in September than in other months. For example, in the latitude band between $30^{\circ} \mathrm{S}$ and $10^{\circ} \mathrm{N}$, there were $6665,10495,10738$ and 9486 TES measurements taken in September, October, November and December 2006, respectively. In September 2005, the measurements are distributed earlier in the month, while in September 2006 the measurements are generally later in the month. It is possible that this difference in temporal sampling could account for the observed year-to-year differences in the fraction of elevated PAN over the Amazon region (South America) in September (see Fig. 2). For October, November and December, the TES measurements are spread more evenly throughout each month in both years.

In terms of year-to-year differences, strong differences are observed for northern central Africa in December. December 2005 shows elevated PAN detected with confidence in $45 \%$ of TES observations compared to $30 \%$ in December 2006. GEOS-Chem simulations indicate that PAN concentrations in this region are strongly influenced by biomass burning (see Supplement). The TES CO in this region does not show marked differences between 2005 and 2006 (Logan et al., 2008). We infer from this that the observed yearto-year difference in PAN is not dominated by differences in biomass burning. MEGAN (via GEOS-Chem - see Fig. 3) does show higher monthly mean isoprene emissions over this region in December 2005 versus 2006. The difference in isoprene emissions at specific locations in the orange box in Fig. 1a range from 10 to $50 \%$. The total isoprene emissions for the region were $\sim 13 \%$ higher in December 2005 than in 2006. Since biogenic emissions in the presence of lightning lead to PAN formation, stronger biogenic emissions in 2005 could contribute to higher PAN values. Logan et al. (2008) also note that there was more lightning over much of Africa (including the region considered here) in 2005 compared to 2006. GEOS-Chem simulations showing the sensitivity of PAN to lightning for December 2005 and 2006 are shown in the Supplement. More lightning $\mathrm{NO}_{x}$ in December 2005 than 2006 would also lead to enhanced PAN.

Vertical transport is also a consideration. If the surface emissions were the same, we would expect that stronger convection in a given year would enhance the impact of surface emissions on mid-upper-tropospheric PAN. It would not only enable more efficient lofting of fire smoke but also allow the same quantity of biogenic NMVOC emissions and/or secondary products to contribute more efficiently to aloft PAN 

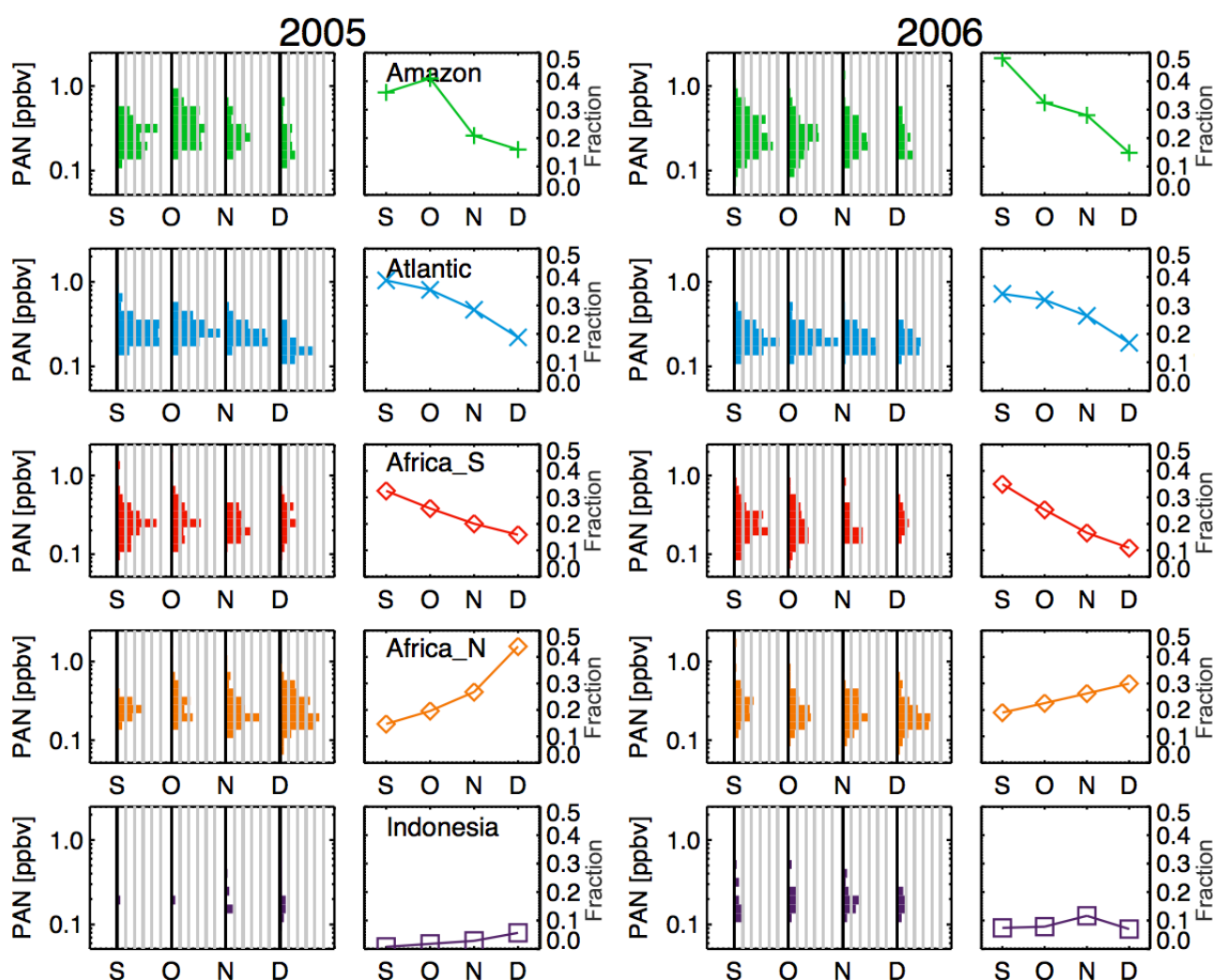

Figure 2. Variation of PAN for different regions in the tropics, as measured by TES, for September through December 2005 (left two columns) and 2006 (right two columns). Two-dimensional histograms show the distribution of PAN values measured by TES for September through December 2005 and 2006 for regions defined by the boxes shown in Fig. 1a - the Amazon region of South America, the tropical south Atlantic, southern central Africa, northern central Africa and Indonesia. Histograms are normalized by the total number of TES observations in that region/month. Line plots show the fraction of TES observations where elevated PAN was detected (colored lines).

formation for a given amount of lightning $\mathrm{NO}_{x}$. Either way, stronger convection in a given year would increase the contribution of surface emissions to PAN in the mid-troposphere, where it can be observed with the nadir-viewing thermalinfrared satellite measurements. Previous studies (e.g., Nassar et al., 2009) have pointed to the difference in convection over northern central Africa between these two years and subsequent differences in $\mathrm{O}_{3}$. Nassar et al. (2009) note that convection was stronger in December 2006 than December 2005 in this region. This would act in the opposite direction to the observed year-to-year PAN differences. We did GEOS-Chem simulations without convection and found that the amount of PAN above northern central Africa is very sensitive to the presence of convection. Transport and scavenging in convective updrafts is coupled in GEOS-Chem (Liu et al., 2001). Turning off the convection operator effectively suppresses both convective transport and scavenging in updrafts. Other related processes, e.g., lightning, $\mathrm{NO}_{x}$ emissions, in-cloud oxidation, all remain. Figure 4 shows maps of the difference in PAN between GEOS-Chem simulations with and without convection. In a global context, northern central Africa is one of the most sensitive regions. The en- hanced convection in November and December 2006 would have acted to increase mid-tropospheric PAN in this region more strongly in 2006 than in 2005. However, the PAN over this region is in fact higher in 2005 than in 2006. Therefore, we conclude that the December year-to-year PAN difference in this region is most likely associated with changes in biogenic emissions and lightning.

A noticeable difference is also observed for Indonesia in October/November, with distinctly higher PAN in 2006 compared to 2005. Logan et al. (2008) have previously discussed extreme CO enhancements in October 2006, associated with the strong 2006 El Niño. During an El Niño event, the normally warm waters and associated convection over the western Pacific and maritime continent move towards the eastern Pacific, resulting in changes in the large-scale circulation. El Niño events are associated with decrease in convection and in precipitation over the maritime continent. The $2006 \mathrm{El}$ Niño was associated with a severe drought in Indonesia, leading to intense fires in this region. The strong enhancements in the CO discussed by Logan et al. (2008) extended into the upper troposphere and lower stratosphere, as seen by the Aura Microwave Limb Sounder (e.g., Zhang et al., 2011). Given 
(a)

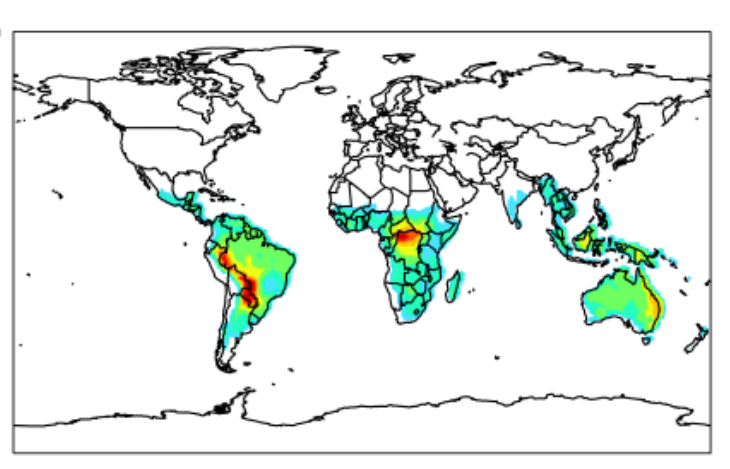

(b)

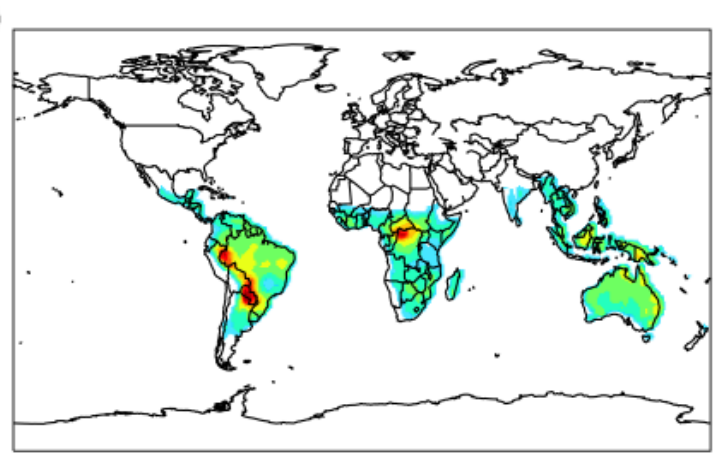

(c)

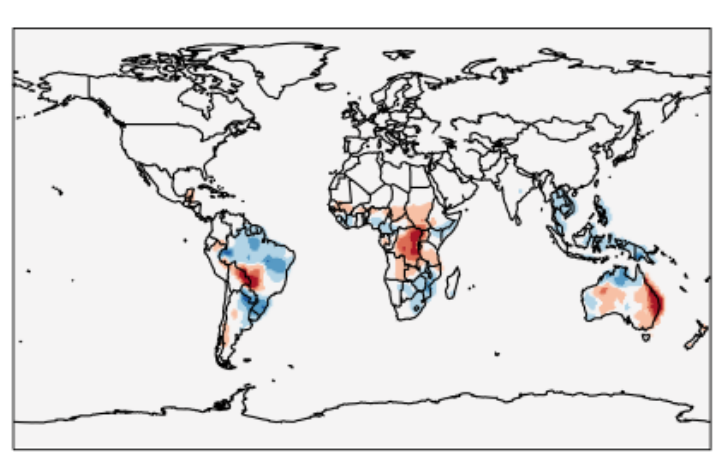

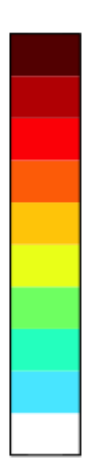

8.00
7.00
6.00
5.00
4.00
3.00
2.00
1.00
0.50
0.25
0.00

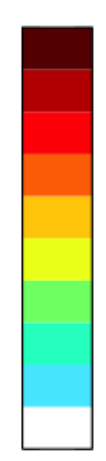

8.00

7.00

6.00

5.00

4.00

3.00

2.00

1.00

0.50

0.25

0.00

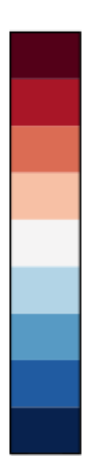

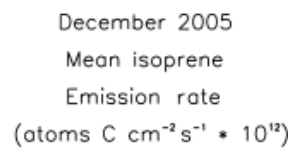

December 2005

Mean isoprene

Emission rate

(atoms $\mathrm{C} \mathrm{cm}^{-2} \mathrm{~s}^{-1} \cdot 10^{12}$ )

5.00

3.00

1.00

0.50

0.10

-0.10 (atoms C cm $\mathrm{cm}^{-2} \mathrm{~s}^{-1} \cdot 10^{12}$ )

$12 / 2005-12 / 2006$

Emission rate Difference
$-0.50$

$-1.00$

$-3.00$

$-5.00$

Figure 3. Monthly mean MEGAN biogenic isoprene emission rate for December 2005 (a) and December 2006 (b). Panel (c) presents the difference in average emission rates between December 2005 and December 2006.

the large $\mathrm{CO}$ emissions from these fires, and the evidence of transport of the $\mathrm{CO}$ to upper altitudes, we might have expected to also observe elevated PAN over Indonesia in October/November 2006. The relationship between PAN and $\mathrm{CO}$ for this region/month is further discussed in Sect. 5. Logan et al. (2008) also highlight that there was more lightning (and therefore higher lightning $\mathrm{NO}_{x}$ emissions) in November and December 2006 than in 2005 by a factor of 2-3, although there was less lightning in October 2006 compared to 2005. Differences in convection and lightning between 2005 and 2006 in this region are further discussed in Nassar et al. (2009).

\section{PAN/CO enhancement and comparisons with GEOS-Chem}

In order to further explore the role of biomass burning on the observed PAN, we use coincident TES measurements of carbon monoxide (CO). Figure 5a and c show scatter plots of TES-retrieved CO versus PAN, for selected regions for October 2005 and 2006. In general, elevated CO in tropical regions can be interpreted as an indication of strong fire emissions. Variability in enhancements in PAN relative to $\mathrm{CO}(\triangle \mathrm{PAN} / \triangle \mathrm{CO})$ in fire plumes is driven by the efficiency of PAN formation, mixing (Yokelson et al. 2013) and transport. For example, in an evaluation of models at high latitudes, Arnold et al. (2015) note that model enhancement ratios show distinct groupings according to the 
(a)

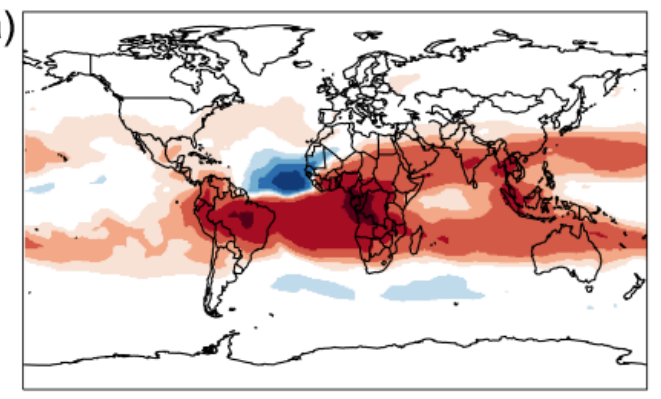

(b)

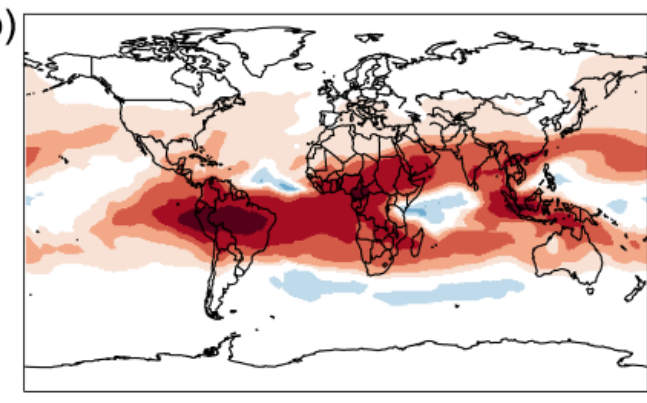

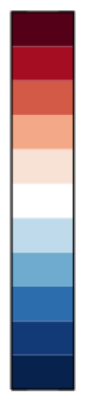

250

50

Dec $20056 \mathrm{~km}$ PAN

Sensitivity to convection

(pptv, convection - no convection)

$-25$

$-100$

$-500$

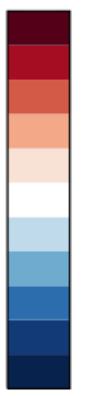

250

50

10 Sensitivity to convection

(pptv, convection - no convection)

$-25$

$-100$

$-500$

Figure 4. Sensitivity of PAN to convection during December 2005 (a) and December 2006 (b) at $6 \mathrm{~km}$ calculated as the difference in PAN between a simulation with and without convection.

meteorological data used to drive the models, which they show is likely linked to differences in vertical transport. Alvarado et al. (2010) discuss aircraft in situ measurements of $\triangle \mathrm{PAN} / \triangle \mathrm{CO}$ in fire plumes sampled during the ARCTAS aircraft campaign. In these high-latitude measurements, Alvarado et al. (2010) report lower values of $\triangle P A N / \Delta C O$ for samples close to the fires, with higher values for samples in the plumes downwind, suggesting PAN formation within the plume. Gray dotted lines show maximum and minimum values of $\triangle \mathrm{PAN} / \triangle \mathrm{CO}$ enhancements in the aircraft measurements of boreal fire plumes reported in Alvarado et al. (2010), assuming a background mid-tropospheric CO value of $50 \mathrm{ppbv}$. These lines are shown here primarily to demonstrate the large range of values in aircraft observations of boreal plumes, not for the purposes of quantitative comparison with these tropical satellite observations. The TES measurements shown in Fig. 5 have not been specifically screened to establish fire influence nor have attempts been made here to categorize the satellite measurements according to distance from fires.

We also compare the TES-retrieved PAN-CO relationships with those from GEOS-Chem. The PAN-CO relationship from GEOS-Chem for October 2005 and 2006 are shown in Fig. 5b and d. When comparing GEOS-Chem modeled PAN with Aura-TES observations, we sampled the model fields at the measurement locations and times. The TES averaging kernels and a priori were applied to the GEOS-Chem profiles in order to account for the sensitivity of the TES measurements. Both the TES measurements and the GEOS-Chem model show a range of $\triangle \mathrm{PAN} / \triangle \mathrm{CO}$ ratios. A

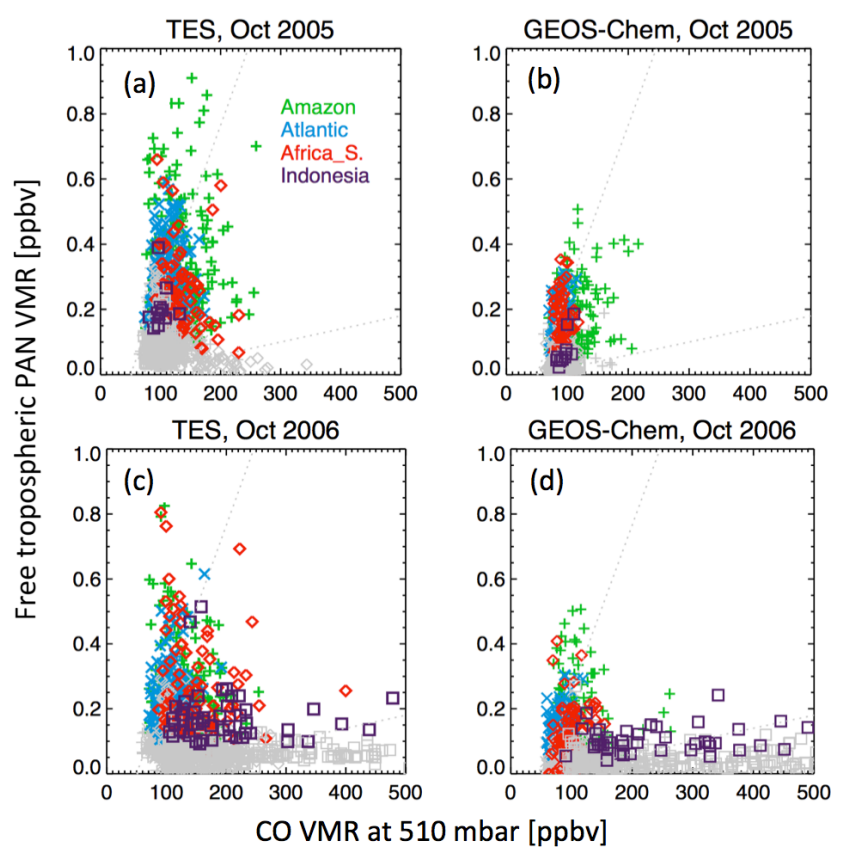

Figure 5. Scatter plots of CO vs. PAN, from TES data and from the GEOS-Chem model, sampled at TES times and locations. Colored symbols show points where TES DOFS $>0.6$ for selected regions (green crosses for the Amazon, blue crosses for the tropical south Atlantic, red diamonds for southern central Africa and purple squares for Indonesia.) Gray symbols show points within any of the selected regions where TES DOFS $<0.6$. Gray dotted lines show maximum and minimum values of $\triangle \mathrm{PAN} / \triangle \mathrm{CO}$ enhancements in aircraft measurements of boreal fire plumes, as reported in Alvarado et al. (2010). 
considerable number of points show $\triangle \mathrm{PAN} / \Delta \mathrm{CO}$ enhancements higher than that previously observed in biomass burning plumes in other regions (Alvarado et al., 2010). We hypothesize that high $\triangle \mathrm{PAN} / \triangle \mathrm{CO}$ enhancements could also conceivably be associated with a strong influence of lightning. Unlike during fires, lightning $\mathrm{NO}_{x}$ is emitted without $\mathrm{CO}$.

The absolute values of PAN are distinctly higher in the measurements than the model. There are a number of possible reasons why the model might predict lower values than observed. One possible reason is a high bias in the observations. Pope et al. (2016), in a comparison between MIPAS PAN results from two different retrieval algorithms, found significant differences in the tropical PAN fields between the two sets of results and pointed to potential reasons for differences that include differences in the way that PAN crosssection data are interpolated within the forward model used in the retrieval algorithm. They concluded that the MIPAS satellite observations are able to detect realistic spatial variations in PAN, but further work is needed to evaluate the satellite retrievals in an absolute sense. We acknowledge that this type of further work is also desirable for evaluation of the results from the TES PAN algorithm. Alternatively, the global model, with its limited spatial resolution, may not be able to capture relatively small-scale plume enhancements that could be observed by the satellite (Rastigejev et al., 2010). It is also possible that the fire injection heights in the model are inaccurate. Other possibilities include underestimation of the $\mathrm{NO}_{x}$-to-PAN conversion ratios in the model or underestimation of the $\mathrm{NO}_{x}$ emissions themselves, from fires, lightning or both.

Although the absolute PAN values from TES are higher than those from GEOS-Chem, we note that both model and measurements show features that are qualitatively consistent in terms of the $\triangle \mathrm{PAN} / \triangle \mathrm{CO}$ relationship. Both model and measurements show a distinctive signature associated with the October 2006 Indonesian fires, extremely elevated CO and distinctly low $\triangle \mathrm{PAN} / \triangle \mathrm{CO}$ enhancement ratios. The low $\triangle \mathrm{PAN} / \triangle \mathrm{CO}$ could be due to two factors: (1) we expect a higher emission ratio of $\mathrm{CO}$ relative to $\mathrm{NO}_{x}$ for peat burning compared to both tropical forests and crop residue (Akagi et al., 2011; Stockwell et al., 2014) and (2) these plumes were not directly injected into the free troposphere, promoting the decomposition of PAN (Tosca et al., 2011).

We used GEOS-Chem to assess the sensitivity of the model to injection height. For October 2005 and 2006, runs were performed both for the default case where $35 \%$ of the of fire emissions are injected into the 10 model layers above the boundary layer and for the case where all fire emissions are injected directly into the planetary boundary layer. We found that at least over Indonesia, the modeled free-tropospheric PAN is not strongly sensitive to the injection height. The difference between the PAN for two runs was $10 \%$ at most (see Fig. 6). A possible reason for this is that the persistent convection in this region enables rapid lofting of PAN
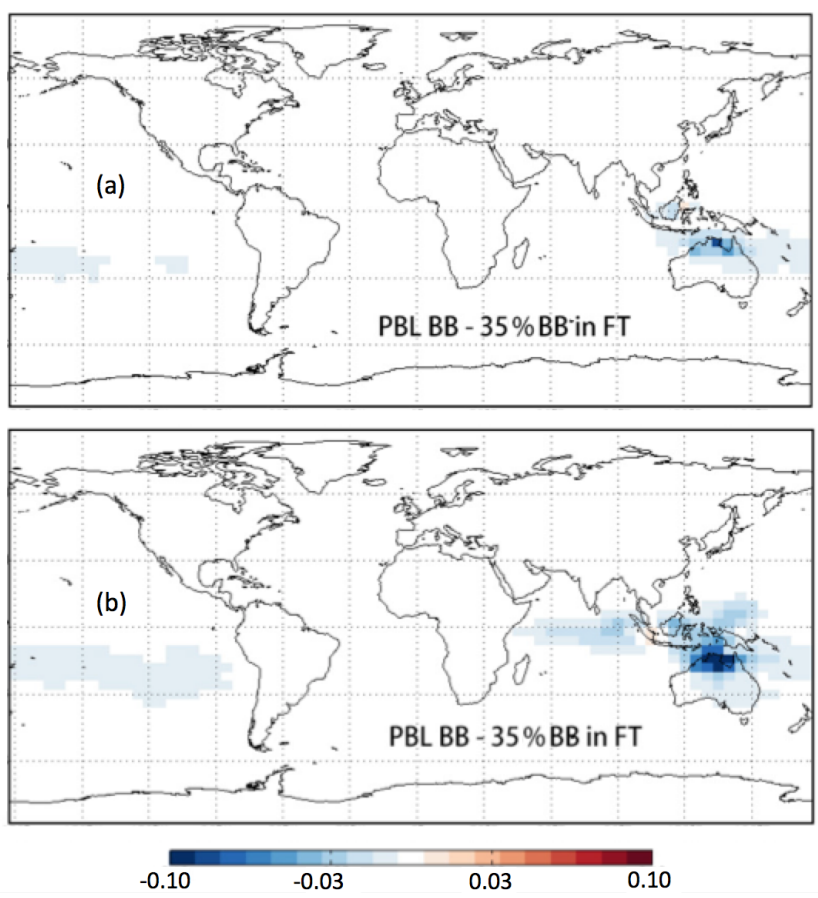

Figure 6. Model sensitivity of free-tropospheric PAN to injection height. (a) Difference between a GEOS-Chem simulation where all fire emissions over Indonesia are injected directly into the planetary boundary layer (PBL) and a simulation where $35 \%$ of fire emissions over Indonesia are injected above the PBL, for October 2005. (b) Same as (a) but for October 2006. Scales are fractional difference.

to the free troposphere, regardless of whether the fire injection heights are within the boundary layer or above it. The model sensitivity result suggests that the higher emission ratio of $\mathrm{CO}$ relative to $\mathrm{NO}_{x}$ for peat burning compared to tropical forests/crop residue is the dominant reason for the low $\triangle \mathrm{PAN} / \triangle \mathrm{CO}$ observed for the Indonesian fires.

When similar runs were performed for December in northern central Africa (not shown), the difference in freetropospheric PAN was up to $40 \%$, indicating that sensitivity to injection height is stronger in that region. The temperature in the lower atmosphere may also factor into the difference in sensitivity to injection heights between different regions.

\section{Conclusions}

Our findings can be summarized as follows: we observe elevated free-tropospheric PAN over the tropical south Atlantic in austral spring for the two years investigated (2005 and 2006). This feature has been predicted by models and previously observed in MIPAS satellite observations of the uppermost troposphere. The TES observations presented here provide confirmation that this feature is also observed in the nadir view. We see a strong enhancement in PAN over northern central Africa $\left(5^{\circ} \mathrm{S}\right.$ to $\left.10^{\circ} \mathrm{N}\right)$ in December 2005 
relative to December 2006. Since convection was stronger in December 2006 than December 2005 in this region, we hypothesize that the December year-to-year PAN difference in this region is most likely associated with changes in biogenic emissions and lightning. We observe small enhancements in free-tropospheric PAN and high enhancements in $\mathrm{CO}$ in October/November 2006 compared to 2005, corresponding to the extreme burning event over Indonesia associated with the 2006 El Niño. Comparisons between the TES observations and the GEOS-Chem model show qualitative agreement in observed regional and year-to-year variations in $\triangle \mathrm{PAN} / \triangle \mathrm{CO}$ enhancement ratios.

Knowledge of the PAN distribution is key to understanding the reactive nitrogen $\left(\mathrm{NO}_{y}\right)$ budget that controls the tropospheric $\mathrm{O}_{3}$. These new nadir-viewing satellite observations of PAN, analyzed in conjunction with a global chemical transport model, demonstrate the importance of emissions, chemistry and transport in understanding the largescale distribution of PAN. TES PAN retrievals will be routinely processed for the entire TES data record, from 2004 to the present, in the TES version 7 data release. We suggest that nadir satellite observations of PAN will complement the existing limb satellite observations and will provide a powerful tool in understanding the reactive nitrogen budget and the global transport of pollution from polluting to receptor regions.

Data availability. TES PAN and CO data are archived at the NASA Langley Research Center Atmospheric Science Data Center (https://eosweb.larc.nasa.gov/project/tes/tes_table, TES Science Team 2013, 2017a, b). The TES products can also be accessed via the NASA Reverb tool (http://reverb.echo.nasa.gov). TES monthly Lite files are also available via the Aura Validation Data Center (http://avdc.gsfc.nasa.gov). The PAN dataset used in this work, produced using a prototype algorithm developed prior to the TES v07 Level 2 release, may be obtained upon request from the corresponding author (vivienne.h.payne@jpl.nasa.gov).

\section{The Supplement related to this article is available online at doi:10.5194/acp-17-6341-2017-supplement.}

Competing interests. The authors declare that they have no conflict of interest.

Disclaimer. Part of this research was carried out at the Jet Propulsion Laboratory, California Institute of Technology, under a contract with the National Aeronautics and Space Administration. Reference herein to any specific commercial product, process or service by trade name, trademark, manufacturer or otherwise does not constitute or imply its endorsement by the United States Government or the Jet Propulsion Laboratory, California Institute of Technology.
Acknowledgements. This work was supported by NASA award number NNX14AF14G.

Edited by: R. Müller

Reviewed by: two anonymous referees

\section{References}

Akagi, S. K., Yokelson, R. J., Wiedinmyer, C., Alvarado, M. J., Reid, J. S., Karl, T., Crounse, J. D., and Wennberg, P. O.: Emission factors for open and domestic biomass burning for use in atmospheric models, Atmos. Chem. Phys., 11, 4039-4072, doi:10.5194/acp-11-4039-2011, 2011.

Alvarado, M. J., Logan, J. A., Mao, J., Apel, E., Riemer, D., Blake, D., Cohen, R. C., Min, K.-E., Perring, A. E., Browne, E. C., Wooldridge, P. J., Diskin, G. S., Sachse, G. W., Fuelberg, H., Sessions, W. R., Harrigan, D. L., Huey, G., Liao, J., Case-Hanks, A., Jimenez, J. L., Cubison, M. J., Vay, S. A., Weinheimer, A. J., Knapp, D. J., Montzka, D. D., Flocke, F. M., Pollack, I. B., Wennberg, P. O., Kurten, A., Crounse, J., Clair, J. M. St., Wisthaler, A., Mikoviny, T., Yantosca, R. M., Carouge, C. C., and Le Sager, P.: Nitrogen oxides and PAN in plumes from boreal fires during ARCTAS-B and their impact on ozone: an integrated analysis of aircraft and satellite observations, Atmos. Chem. Phys., 10, 9739-9760, doi:10.5194/acp-10-9739-2010, 2010.

Alvarado, M. J., Cady-Pereira, K. E., Xiao, Y., Millet, D. B., and Payne, V. H.: Emission Ratios for Ammonia and Formic Acid and Observations of Peroxy Acetyl Nitrate (PAN) and Ethylene in Biomass Burning Smoke as Seen by the Tropospheric Emission Spectrometer (TES), Atmosphere 2, 633-654, 2011.

Anderson, B. E., Gregory, G. L., Barrick, J. D. W., Collins, J. E., Sachse, G. W., Hudgins, C. H., Bradshaw, G. D., and Sandholm, S. T., Factors influencing dry season ozone distributions over the tropical South Atlantic, J. Geophys. Res., 98, 23491-23500, doi:10.1029/93JD01361, 1993.

Arnold, S. R., Emmons, L. K., Monks, S. A., Law, K. S., Ridley, D. A., Turquety, S., Tilmes, S., Thomas, J. L., Bouarar, I., Flemming, J., Huijnen, V., Mao, J., Duncan, B. N., Steenrod, S., Yoshida, Y., Langner, J., and Long, Y.: Biomass burning influence on high-latitude tropospheric ozone and reactive nitrogen in summer 2008: a multi-model analysis based on POLMIP simulations, Atmos. Chem. Phys., 15, 6047-6068, doi:10.5194/acp15-6047-2015, 2015.

Clarisse, L., R'Honi, Y., Coheur, P.-F., Hurtmans, D., and Clerbaux, C.: Thermal infrared nadir observations of 24 atmospheric gases, Geophys. Res. Lett., 38, 10802, doi:10.1029/2011GL047271, 2011.

Edwards, D. P., Lamarque, J.-F., Attie, J.-L., Emmons, L. K., Richter, A., Cammas, J.-P., Gille, J. C., Francis, G. L., Deeter, M. N., Warner, J., Ziskin, D. C., Lyjak, L. V., Drummond, J. R., and Burrows, J. P.: Tropospheric ozone over the tropical Atlantic: A satellite perspective, J. Geophys. Res., 108, 4237, doi:10.1029/2002JD002927, 2003.

Fadnavis, S., Schultz, M. G., Semeniuk, K., Mahajan, A. S., Pozzoli, L., Sonbawne, S., Ghude, S. D., Kiefer, M., and Eckert, E.: Trends in peroxyacetyl nitrate (PAN) in the upper troposphere and lower stratosphere over southern Asia during the sum- 
mer monsoon season: regional impacts, Atmos. Chem. Phys., 14, 12725-12743, doi:10.5194/acp-14-12725-2014, 2014.

Fischer, E. V., Jacob, D. J., Yantosca, R. M., and Sulprizio, M.: The effect of peroxyacetyl nitrate (PAN) chemistry on global oxidant distributions, Abstract A23J-06 presented at 2013 Fall Meeting, 9-13 December 2013, AGU, San Francisco, CA, USA, 2013.

Fischer, E. V., Jacob, D. J., Yantosca, R. M., Sulprizio, M. P., Millet, D. B., Mao, J., Paulot, F., Singh, H. B., Roiger, A., Ries, L., Talbot, R. W., Dzepina, K., and Pandey Deolal, S.: Atmospheric peroxyacetyl nitrate (PAN): a global budget and source attribution, Atmos. Chem. Phys., 14, 2679-2698, doi:10.5194/acp-142679-2014, 2014.

Glatthor, N., von Clarmann, T., Fischer, H., Funke, B., Grabowski, U., Höpfner, M., Kellmann, S., Kiefer, M., Linden, A., Milz, M., Steck, T., and Stiller, G. P.: Global peroxyacetyl nitrate (PAN) retrieval in the upper troposphere from limb emission spectra of the Michelson Interferometer for Passive Atmospheric Sounding (MIPAS), Atmos. Chem. Phys., 7, 2775-2787, doi:10.5194/acp7-2775-2007, 2007.

Gregory, G. L., Fuelberg, H. E., Longmore, S. P., Anderson, B. E., Collins, J. E., and Blake, D. R.: Chemical characteristics of tropospheric air over the tropical South Atlantic Ocean: Relationship to trajectory history, J. Geophys. Res., 101, 23957-23972, doi:10.1029/96jd01160, 1996.

Guenther, A., Karl, T., Harley, P., Wiedinmyer, C., Palmer, P. I., and Geron, C.: Estimates of global terrestrial isoprene emissions using MEGAN (Model of Emissions of Gases and Aerosols from Nature), Atmos. Chem. Phys., 6, 3181-3210, doi:10.5194/acp-63181-2006, 2006.

Hewitt, C. N., Lee, J. D., MacKenzie, A. R., Barkley, M. P., Carslaw, N., Carver, G. D., Chappell, N. A., Coe, H., Collier, C., Commane, R., Davies, F., Davison, B., DiCarlo, P., Di Marco, C. F., Dorsey, J. R., Edwards, P. M., Evans, M. J., Fowler, D., Furneaux, K. L., Gallagher, M., Guenther, A., Heard, D. E., Helfter, C., Hopkins, J., Ingham, T., Irwin, M., Jones, C., Karunaharan, A., Langford, B., Lewis, A. C., Lim, S. F., MacDonald, S. M., Mahajan, A. S., Malpass, S., McFiggans, G., Mills, G., Misztal, P., Moller, S., Monks, P. S., Nemitz, E., Nicolas-Perea, V., Oetjen, H., Oram, D. E., Palmer, P. I., Phillips, G. J., Pike, R., Plane, J. M. C., Pugh, T., Pyle, J. A., Reeves, C. E., Robinson, N. H., Stewart, D., Stone, D., Whalley, L. K., and Yin, X.: Overview: oxidant and particle photochemical processes above a south-east Asian tropical rainforest (the OP3 project): introduction, rationale, location characteristics and tools, Atmos. Chem. Phys., 10, 169-199, doi:10.5194/acp-10-169-2010, 2010.

Jacob, D. J., Heikes, E. G., Fan, S-M., Logan, J. A., Mauzerall, D. L., Bradshaw, J. D., Singh, H. B., Gregory, G. L., Talbot, R. W., Blake, D. R., and Sachse, G. W.: Origin of ozone and $\mathrm{NO}_{x}$ in the tropical troposphere: A photochemical analysis of aircraft observations over the South Atlantic basin, J. Geophys. Res., 101, 24235-24250, doi:10.1029/96jd00336, 1996.

Jiang, Z., Worden, J. R., Payne, V. H., Zhu, L., Fischer, E., Walker, T., and Jones, D. B. A.: Ozone export from East Asia: The role of PAN, J. Geophys. Res., 121, 6555-6563, doi:10.1002/2016JD024952, 2016.

Kulawik, S. S., Worden, J., Eldering, A., Bowman, K., Gunson, M., Osterman, G. B., Zhang, L., Clough, S., Shephard, M. W., and Beer, R.: Implementation of cloud retrievals for Tropospheric Emission Spectrometer (TES) atmospheric retrievals: part 1. De- scription and characterization of errors on trace gas retrievals, J. Geophys. Res., 111, D24204, doi:10.1029/2005JD006733, 2006.

Liu, H., Jacob, D. D., Bey, I., and Yantosca, R. M.: Constraints from ${ }^{210} \mathrm{~Pb}$ and ${ }^{7} \mathrm{Be}$ on wet deposition and transport in a global three-dimensional chemical tracer model driven by assimilated meteorological fields, J. Geophys. Res., 106, 1210912128, 2001.

Logan, J. A., Megretskaia, I., Nassar, R., Murray, L. T., Zhang, L., Bowman, K. W., Worden, H. M., and Luo, M.: Effects of the $2006 \mathrm{El}$ Nino on tropospheric composition as revealed by data from the Tropospheric Emission Spectrometer (TES), Geophys Res. Lett., 35, L03816, doi:10.1029/2007GL031698, 2008.

Maloney, J. C., Fuelberg, H. E.,Avery, M. A., Crawford, J. H., Blake, D. R., Heikes, B. G., Sachse, G. W., Sandholm, S. T., Singh, H., and Talbot, R. W.: Chemical characteristics of air from different source regions during the second Pacific Exploratory Mission in the Tropics (PEM-Tropics B), J. Geophys. Res., 106, 32609-32625, doi:10.1029/2001JD900100, 2001.

Moore, D. P. and Remedios, J. J.: Seasonality of Peroxyacetyl nitrate (PAN) in the upper troposphere and lower stratosphere using the MIPAS-E instrument, Atmos. Chem. Phys., 10, 6117-6128, doi:10.5194/acp-10-6117-2010, 2010.

Nassar, R., Logan, J. A., Megretskaia, I. A., Murray, L. T., Zhang, L., and Jones, D. B. A.: Analysis of tropical tropospheric ozone, carbon monoxide and water vapor during the 2006 El Niño using TES observations and the GEOS-Chem model, J. Geophys. Res., 114, D17304, doi:10.1029/2009JD011760, 2009.

Paulot, F., Crounse, J. D., Kjaergaard, H. G., Kroll, J. H., Seinfeld, J. H., and Wennberg, P. O.: Isoprene photooxidation: new insights into the production of acids and organic nitrates, Atmos. Chem. Phys., 9, 1479-1501, doi:10.5194/acp-9-1479-2009, 2009a.

Paulot, F., Crounse, J. D., Kjaergaard, H. G., Kürten, A., St. Clair, J. M., Seinfeld, J. H., and Wennberg, P. O.: Unexpected Epoxide Formation in the Gas-Phase Photooxidation of Isoprene, Science, 325, 730-733, doi:10.1126/science.1172910, $2009 \mathrm{~b}$.

Payne, V. H., Alvarado, M. J., Cady-Pereira, K. E., Worden, J. R., Kulawik, S. S., and Fischer, E. V.: Satellite observations of peroxyacetyl nitrate from the Aura Tropospheric Emission Spectrometer, Atmos. Meas. Tech., 7, 3737-3749, doi:10.5194/amt-7-37372014, 2014.

Pope, R. J., Richards, N. A. D., Chipperfield, M. P., Moore, D. P., Monks, S. A., Arnold, S. R., Glatthor, N., Kiefer, M., Breider, T. J., Harrison, J. J., Remedios, J. J., Warneke, C., Roberts, J. M., Diskin, G. S., Huey, L. G., Wisthaler, A., Apel, E. C., Bernath, P. F., and Feng, W.: Intercomparison and evaluation of satellite peroxyacetyl nitrate observations in the upper troposphere-lower stratosphere, Atmos. Chem. Phys., 16, 13541-13559, doi:10.5194/acp-16-13541-2016, 2016.

Rastigejev, Y., Park, R., Brenner, M. P., and Jacob, D. J.: Resolving intercontinental pollution plumes in global models of atmospheric transport, J. Geophys. Res.-Atmos., 115, D02302, doi:10.1029/2009JD012568, 2010.

Roberts, J. M., Marchewka, M., Bertman, S. B., Sommariva, R., Warneke, C., de Gouw, J., Kuster, W., Goldan, P., Williams, E., Lerner, B. M., Murphy, P., and Fehsenfeld, F. C.: Measurements of PANs during the New England Air Quality Study 2002, J. Geophys. Res., 112, D20306, doi:10.1029/2007JD008667, 2007.

Singh, H. B. and Hanst, P. L.: Peroxyacetyl nitrate (PAN) in the unpolluted atmosphere: an important reservoir 
for nitrogen oxides, Geophys. Res. Lett., 8, 941-944, doi:10.1029/GL008i008p00941, 1981.

Singh, H. B., Herlth, D., Kolyer, R., Chatfield, R., Viezee, W., Salas, L. J., Chen, Y., Bradshaw, J. D., Sandholm, S. T., Talbot, R., Gregory, G. L., Anderson, B., Sachse, G. W., Browell, E., Bachmeier, A. S., Blake, D. R., Heikes, B., Jacob, D., and Fuelberg H. E.: Impact of biomass burning emissions on the composition of the South Atlantic troposphere: Reactive nitrogen and ozone, J. Geophys. Res., 101, 24203-24219, doi:10.1029/96jd01018, 1996.

Stockwell, C. E., Yokelson, R. J., Kreidenweis, S. M., Robinson, A. L., DeMott, P. J., Sullivan, R. C., Reardon, J., Ryan, K. C., Griffith, D. W. T., and Stevens, L.: Trace gas emissions from combustion of peat, crop residue, domestic biofuels, grasses, and other fuels: configuration and Fourier transform infrared (FTIR) component of the fourth Fire Lab at Missoula Experiment (FLAME4), Atmos. Chem. Phys., 14, 9727-9754, doi:10.5194/acp-149727-2014, 2014.

Tereszchuk, K. A., Moore, D. P., Harrison, J. J., Boone, C. D., Park, M., Remedios, J. J., Randel, W. J., and Bernath, P. F.: Observations of peroxyacetyl nitrate (PAN) in the upper troposphere by the Atmospheric Chemistry Experiment-Fourier Transform Spectrometer (ACE-FTS), Atmos. Chem. Phys., 13, 5601-5613, doi:10.5194/acp-13-5601-2013, 2013.

TES Science Team: TES/Aura Level 2, Carbon Monoxide Lite Nadir, version 6, Hampton, VA, USA, NASA Atmospheric Science Data Center (ASDC), available at: doi:10.5067/AURA/TES/TL2COLN_L2.006 (last access: March 2016), 2013.

TES Science Team: TES/Aura Level 2, Peroxyacyl Nitrate Nadir, version 7, Hampton, VA, USA, NASA Atmospheric Science Data Center (ASDC), available at: doi:10.5067/AURA/TES/TL2PANN_L2.007 (last access: 20 April 2017), 2017a.

TES Science Team: TES/Aura Level 2, Carbon Monoxide Nadir, version 7, Hampton, VA, USA, NASA Atmospheric Science Data Center (ASDC), available at: doi:10.5067/AURA/TES/TESCON_L2.007 (last access: 20 April 2017), 2017b.

Tosca, M. G., Randerson, J. T., Zender, C. S., Nelson, D. L., Diner, D. J., and Logan, J. A.: Dynamics of fire plumes and smoke clouds associated with peat and deforestation fires in Indonesia, J. Geophys. Res., 116, D08207, doi:10.1029/2010JD015148, 2011.
Ungermann, J., Ern, M., Kaufmann, M., Müller, R., Spang, R., Ploeger, F., Vogel, B., and Riese, M.: Observations of PAN and its confinement in the Asian summer monsoon anticyclone in high spatial resolution, Atmos. Chem. Phys., 16, 8389-8403, doi:10.5194/acp-16-8389-2016, 2016.

Val Martin, M., Logan, J. A., Kahn, R. A., Leung, F.-Y., Nelson, D. L., and Diner, D. J.: Smoke injection heights from fires in North America: analysis of 5 years of satellite observations, Atmos. Chem. Phys., 10, 1491-1510, doi:10.5194/acp-10-14912010, 2010.

Wang, Y., Logan, J. A., and Jacob, D. J.: Global simulation of tropospheric $\mathrm{O}_{3}-\mathrm{NO}_{x}$-hydrocarbon chemistry, 2. Model evaluation and global ozone budget, J. Geophys. Res., 103, 10727-10755, 1998.

Wiegele, A., Glatthor, N., Höpfner, M., Grabowski, U., Kellmann, S., Linden, A., Stiller, G., and von Clarmann, T.: Global distributions of $\mathrm{C}_{2} \mathrm{H}_{6}, \mathrm{C}_{2} \mathrm{H}_{2}, \mathrm{HCN}$, and PAN retrieved from MIPAS reduced spectral resolution measurements, Atmos. Meas. Tech., 5, 723-734, doi:10.5194/amt-5-723-2012, 2012.

Yokelson, R. J., Andreae, M. O., and Akagi, S. K.: Pitfalls with the use of enhancement ratios or normalized excess mixing ratios measured in plumes to characterize pollution sources and aging, Atmos. Meas. Tech., 6, 2155-2158, doi:10.5194/amt-62155-2013, 2013.

Zhang, L., Li, Q. B., Jin, J., Liu, H., Livesey, N., Jiang, J. H., Mao, Y., Chen, D., Luo, M., and Chen, Y.: Impacts of 2006 Indonesian fires and dynamics on tropical upper tropospheric carbon monoxide and ozone, Atmos. Chem. Phys., 11, 10929-10946, doi:10.5194/acp-11-10929-2011, 2011.

Zhu, L., Fischer, E. V., Payne, V. H., Worden, J. R., and Jiang, Z.: TES observations of the interannual variability of PAN over Northern Eurasia and the relationship to springtime fires, Geophys. Res. Lett., 42, 7230-7237, doi:10.1002/2015GL065328, 2015.

Zhu, L., Fischer, E. V., Payne, V. H., Walker, T. W., Worden, J. R., Jiang, Z., and Kulawik, S. S.: PAN in the Eastern Pacific Free Troposphere: A Satellite View of the Sources, Seasonality, Interannual Variability and Timeline for Trend Detection, J. Geophys. Res., 122, 3614-3629, doi:10.1002/2016JD025868, 2017.

Ziemke, J. R., Chandra, S., Duncan, B. N., Schoeberl, M. R., Torres, O., Damon, M. R., and Bhartia, P. K.: Recent biomass burning in the tropics and related changes in tropospheric ozone, Geophys. Res. Lett., 36, L15819, doi:10.1029/2009GL039303, 2009. 